\title{
Mind the Gap: Internet Pornography Exposure, Influence and Problematic Viewing Amongst Emerging Adults
}

\author{
Shireen Bernstein ${ }^{1}$ D $\cdot$ Wayne Warburton $^{1} \cdot$ Kay Bussey $^{1} \cdot$ Naomi Sweller $^{1}$
}

Accepted: 9 February 2022

(c) The Author(s) 2022

\begin{abstract}
Introduction Characterised by both exploration and engagement in risky behaviours, late adolescence and emerging adulthood are periods of particular vulnerability to dysregulated behaviours. One such behaviour less well explored is that of problematic Internet pornography (IP) viewing, despite viewing explicit online material becoming increasingly pervasive and normative.

Method In 2020, 385 (270 females, 110 males) Australian undergraduate students (aged 17-25 years) completed an online survey assessing exposure to IP, affective and cognitive responses to IP, IP-related sexual beliefs, self-assessed problematic IP viewing and key psychological vulnerability factors. Correlational and regression analyses were utilised to assess the relationships between variables.

Results Most male (57.3\%) and female (33.7\%) respondents recalled their first exposure to IP as occurring between 12 and 14 years; however, $28.2 \%$ of males and $23.7 \%$ females recalled their exposure as occurring between 9 and 11 years, and a small proportion were exposed even earlier. Higher IP viewing frequency, positive affective responses to IP at current exposure, elevated sexual impulsivity and the endorsement of IP-related sexual beliefs were all found to be associated with self-assessed problematic IP viewing.

Conclusions Findings suggest that both person and situational factors may contribute to problematic IP viewing patterns. IP viewing may also be shaping the sexual beliefs and behaviours of some viewers.

Policy Implications There is little consensus on the factors that may lead IP viewing to become problematic, which limits the ability of clinicians to identify more susceptible individuals. These findings suggest that in addition to dysregulation factors such as sexual impulsivity, dissociation and depression, affective responses to IP and IP-related beliefs may also be important to consider when assessing for whom IP viewing may become problematic.
\end{abstract}

Keywords Internet pornography $\cdot$ Young adults $\cdot$ Sexual socialisation $\cdot$ Media psychology $\cdot$ Sexuality

The period of late adolescence to emerging adulthood (17-25 years) is a significant stage of development, often characterised by exploration in the areas of sexuality, romantic relationships, identity and values, as well increased participation in risky behaviours (Arnett, 2006; Sussman \& Arnett, 2014). One aspect of sexual behaviour that has been less well explored is that of problematic Internet pornography (PIP) use, despite IP viewing being both widespread and increasingly normative (Brown et al., 2017; Carroll et al.,

Shireen Bernstein

shireen.bernstein@students.mq.edu.au

1 Department of Psychology, Faculty of Medicine, Health and Human Sciences, Macquarie University, Sydney, NSW 2109, Australia
2008; Häggström-Nordin et al., 2005; Hald, 2006; Lim et al., 2017). In studies of self-perceived effects of pornography consumption, both men and women have reported small to moderate positive effects and few, if any negative effects (Hald \& Malamuth, 2008; McKee, 2008; Miller et al., 2018). However, the tendency to minimise any negative effects from IP, or to believe that others are more vulnerable to its effects, is also not uncommon (Lee \& Tamborini, 2005; Lo $\&$ Wei, 2002). Even if an individual does not consider their IP viewing is problematic, it may nevertheless guide some of their sexual beliefs and behaviours. The likelihood and the manner in which IP may influence its viewers depend on many factors, including individual evaluations of the depicted conduct, personal beliefs about the acceptability of IP and partner approval, amongst others (Döring, 2009; 
Häggström-Nordin et al., 2006; Lim et al., 2017; Rissel et al., 2017).

Empirical studies examining these attitudinal processes are limited, and there is no widely accepted means of defining PIP use (Grubbs et al., 2010). Research is likewise limited in its examination of the factors that may encourage IP consumption to become problematic for some users but not for others (Cooper et al., 2004; Harper \& Hodgins, 2016; Twohig et al., 2009). This restricts the means by which clinicians can detect and treat "at-risk" IP consumers. Some evidence suggests that psychological factors such as impulse control and depressive symptomatology (Antons \& Brand, 2018; Morahan-Martin, 2005; Svedin et al., 2011) and exposure factors such as age of first exposure, positive cognitive expectancies and biases about IP (Brand et al., 2016) and frequency of IP viewing (Harper \& Hodgins, 2016; Ross et al., 2012) may play a role in the development of PIP viewing. Currently, however, no study has attempted to reconcile these predisposing factors in a single study. This study aims to fill this gap by exploring the individual cognitive expectancy and exposure-related factors as well as the psychopathological predisposing factors that may lead a young adult to be more susceptible to PIP viewing. It is also relevant to consider whether these factors are also related to the likelihood that an individual will incorporate IP-inspired sexual practices into their sexual lives, potentially generating individual or relational difficulties (Maddox et al., 2011; Stewart \& Szymanski, 2012; Štulhofer et al., 2010).

\section{Defining Problematic IP Viewing}

Unlike occasional viewing of IP, PIP viewing is thought to have significant emotional, psychosocial and relational impacts, such as guilt, increased body surveillance and dissatisfaction and relationship discord (Grubbs et al., 2015; Stewart \& Szymanski, 2012; Tylka, 2015; Tylka \& Kroon Van Diest, 2015). One useful definition of PIP use is any level of use that creates inter-personal, intra-personal or vocational difficulties (Twohig et al., 2009). It is also germane to consider whether an individual "feels" their IP viewing is problematic, as this can reliably predict psychological distress (Grubbs et al., 2019). A recent study found that scores on the Cyber Pornography Use Inventory-9 (CPUI-9), a self-assessed IP addiction scale, were indeed reflective of actual compulsive viewing (Fernandez et al., 2017). Self-perceptions have also been found to overshadow objective measures, such as daily use of IP, in predicting negative psychosocial outcomes (Grubbs et al., 2015, 2017). Accordingly, this study will also utilise a self-assessed PIP use measure.

\section{IP Usage Consequences}

Previous research on the consequences of IP viewing draws inconsistent conclusions, with studies finding both negative and positive outcomes (see Weitzer, 2011; Wright et al., 2016). Detrimental outcomes include being more critical of one's own or a partner's body (Albright, 2008; Tylka, 2015), participating in more unsafe sexual and non-sexual behaviours (Carroll et al., 2008; Harkness et al., 2015; Svedin et al., 2011; Wright \& Arroyo, 2013; Wright \& Randall, 2012), and lower relationship or sexual satisfaction (Maddox et al., 2011; Manning, 2006; Stewart \& Szymanski, 2012). However, some studies suggest IP viewing can enhance self-perceived sexual competence and education (Hald \& Malamuth, 2008) and encourage more open-mindedness and comfort with one's sexuality (Innala, 2007; Watson \& Smith, 2012; Weinberg et al., 2010). This divergence in conclusions is less contradictory than it may seem, as there appear to be substantial differences in individual susceptibility to media effects (Valkenburg et al., 2016), and thus, there may be inherent individual characteristics that may make individuals more or less prone to PIP viewing.

\section{Individual and Exposure-related Predisposing Factors for PIP Viewing}

\section{Age of First Exposure and Gender}

Earlier age of initial exposure and gender have both previously been shown to influence cognitions toward and approval of IP (Brown et al., 2017; Carroll et al., 2008; Hald, 2006). In a sample of heterosexual Danish young adults, Hald (2006) found that compared to women, men use pornography significantly more often, are first exposed at a significantly younger age and spend significantly more time per week watching pornography. However, in a similar sample of Polish young adults, Dwulit and Rzymski (2019) found no difference between males and females in the mean age of initial exposure to IP and no difference in the gender of those indicating daily use of IP. Single males exposed to IP at an early age have, however, been found to be most at risk of developing PIP viewing (Harper \& Hodgins, 2016), and viewers exposed to IP at a younger age report more negative consequences than viewers exposed later in life (Miller et al., 2018). In this context, both age of initial exposure to IP and gender will be considered in this study for their association with PIP viewing.

\section{IP Consumption and Sexual Beliefs}

Although IP is a mediated construal often using actors, producers and scripts, IP also seems to affect the "real life" sexual preferences and practices of both men and women. Some studies have found an association between exposure 
to pornography and female participation in particular sexual acts, such as anal intercourse, despite many respondents in these same studies describing this activity as negative and, in some cases, coercive (see Marston \& Lewis, 2014; Rogala \& Tydén, 2003; Tydén et al., 2001). Exposure to IP may also be associated with the normalisation of violence. Both crosssectional and experimental studies with women have found an association between exposure to violent pornography and rape-supportive beliefs and fantasies, increased victim blaming and a corresponding reduction in perceived perpetrator responsibility (Corne et al., 1992; Cowan \& Campbell, 1995; Davis et al., 2006). However, these associations do not demonstrate causation and longitudinal studies are required to clarify the directionality of these effects.

The association of IP with specific sexual beliefs may be driven both via behaviour reinforcement and through cognitive biases (Brand et al., 2016). For example, Peter and Valkenburg (2006) found that recreational attitudes to sex were mediated by how realistic the participant perceived the IP material to be, with male adolescents perceiving IP content as more realistic than female adolescents. Whilst it remains difficult to untangle the directionality of effects, some studies of male IP viewing behaviour have found that the more frequently a particular media script is viewed, the more likely those scripts are to be enacted in offline sexual experiences (Sun et al., 2016; Wright \& Tokunaga, 2016). Importantly, a nationally representative, longitudinal study conducted with US adults found a positive prospective association between pornography exposure and subsequent sexual permissiveness (Wright, 2013). This suggests that what is viewed on the screen may also guide sexual beliefs and behaviours offline. In terms of reinforcement, it is probable that positive initial emotional responses to IP are associated with subsequent appraisals and viewing frequency of IP, such that these positive expectancies lead viewers to seek out IP more frequently and, for some, to use IP problematically. Thus, it seems relevant to consider emotional responses to IP and the association of IP with specific sexual beliefs, and whether these factors are also associated with PIP viewing.

\section{Psychopathological Predisposing Factors for PIP Viewing}

There is limited research identifying the trait or state factors that make an individual more vulnerable to developing PIP viewing (Antons \& Brand, 2018; Borgogna \& Aita, 2019; Brand et al., 2016). However, the etiological similarities between some Internet use disorders (IUDs) and substance use disorders suggest impulsivity may be a shared vulnerability factor (Brand et al., 2014), which may similarly predispose individuals to PIP viewing. It has also been proposed that IUDs may covary positively with both positive expectancies (to experience pleasure) and avoidance expectancies (to escape from reality) (Brand et al., 2016). Higher pornography use has also been found to correlate with personality factors such as greater anxiety, depression, impulsivity, vulnerability to stress (neuroticism facets) and the fantasy facet of openness to experience (Fagan et al., 1991). A recent conceptual model of pornography-induced problems likewise highlighted factors such as impulsivity, sensation seeking and coping insufficiencies as increasing the tendency towards problematic IP use (Grubbs et al., 2019). In this context, coping insufficiencies in the form of depression and dissociation and the personality factors of sensation seeking and impulsivity will be explored in this study for their association with PIP viewing.

\section{Depression and Dissociation}

Grubbs et al. (2015) have described a bi-directional effect between PIP viewing and depression, in that the rumination associated with depression could lead an individual to negatively interpret their viewing of IP and likewise, PIP use could itself be a coping mechanism for psychological distress. Cooper et al. (1999) have similarly suggested a taxonomy of online sexual activity (OSA) identifying the depressive and fantasy user as two of the subtypes of OSA users more at risk of developing problematic behaviour. They describe the "depressive subtype" as seeking relief from their depression, whilst the "fantasy subtype" may engage with online sexual content in a "trance-like state of mind" constantly seeking the ideal image or video that fulfils their favourite erotic fantasy (Cooper et al., 2004, p. 135). This fantasy state also allows individuals to engage with sexual activities and behaviours they may feel are unacceptable offline, with dissociation potentially facilitating this disconnection, and permitting the disavowal of aspects of the self (Braun, 1988). Thus, both depression and dissociation will be examined in this study for their association with PIP viewing.

\section{Sexual Impulsivity and Sensation Seeking}

Impulsivity has been described as the tendency to act rashly and without forethought (Dalley et al., 2011) and may be understood both in terms of the relatively stable impulsivity personality trait and in terms of state impulsivity, which is conditional on environmental and affective factors (Wiers et al., 2010). Trait impulsivity has been identified as an important predisposing factor in behavioural addictions such as gambling disorder (Choi et al., 2014; Lee et al., 2012), and what has been described as Internet pornography use disorder (Antons \& Brand, 2018; Laier \& Brand, 2017). Similarly, the trait of sensation seeking refers to the seeking of novel, multifarious and intense sensations and experiences as well as a willingness to take risks (be they physical, social or otherwise) simply for the stimulation such experiences offer (Lu et al., 2014). 
Sensation-seeking individuals tend to seek experiences which increase their level of arousal, and studies suggest this can result in a higher intention to accept or engage in dangerous sexual behaviour, such as eschewing condom use (Noar et al., 2006).

\section{The Present Study}

An online survey of undergraduate students was administered to ascertain whether there are exposure, affective, cognitive and psychopathological factors that may be associated with self-assessed PIP viewing. In this context, the following hypotheses are proposed:

H1: Recalled initial emotional responses to IP will be associated with subsequent cognitive appraisals and viewing frequency of IP. Accordingly, it is expected that recalled positive affective responses to IP will be positively correlated with higher viewing frequency and negatively correlated with a negative cognitive appraisal of IP. Negative affective responses to IP at initial exposure and current exposure will both be significantly associated with a negative cognitive appraisal of IP.

H2: Earlier exposure and more frequent IP viewing will be correlated with PIP viewing. It is also expected that compared to females, male respondents will indicate being exposed to IP earlier than females, will cognitively appraise IP less negatively, will view IP more frequently and will be more likely to identify their IP viewing as problematic.

H3: Given the ubiquity of IP, we expect there will be no significant difference on the IP-related sexual beliefs measure when comparing males and females, with both genders equally likely to indicate IP inspires their sexual beliefs.

H4: PIP viewing will be positively associated with sexual impulsivity, depression, dissociative tendencies and IP-related sexual beliefs. It is expected that earlier age of initial exposure to IP, higher IP viewing frequency, higher positive affective responses to IP at initial and current exposure, higher sexual impulsivity, depression and dissociation and higher scores on the IP-related sexual beliefs measure will all uniquely contribute to the prediction of PIP viewing.

\section{Method}

\section{Ethics Approval}

This study was submitted to the University Human Research Ethics Committee, which granted full ethical and scientific approval (Reference No: 5201938136940).

\section{Design and Participants}

A total of 423 responses from undergraduate psychology students were collected via an online questionnaire at a large public university in Australia. Of these, 38 cases were excluded from analysis due to being ineligible to participate: 13 participants had not previously viewed IP, and 25 failed to complete a large proportion of the survey. The final sample $(N=385)$ of respondents were all aged $17-25(63.4 \%$ were $17-19$ years, $21 \%$ were $20-22$ years and $15.6 \%$ were 23-25 years). Of this sample, $70.1 \%$ were female and $28.6 \%$ were male. All participants received course credit for their participation.

\section{Measures}

\section{Demographics, Internet Use and IP Exposure Screener}

Participants were asked to identify their age, gender and their method and frequency of Internet access. Participants were also screened to ensure that they had previously seen IP, defined as: "By pornography, we mean images and films of people having sex or behaving sexually online. This includes semi-naked and naked images and films of people that you may have viewed or downloaded from the Internet, or that someone else shared with you directly, or showed to you on their phone or computer" (Martellozzo et al., 2016).

\section{IP First Exposure}

In addition to being asked the age at which they were first exposed to IP, respondents were also asked about the context of their exposure. This measure provided a retrospective examination of respondents' early exposure to IP and employed a modified version of a scale utilised in a UK study of secondary students (Martellozzo et al., 2016). Novel items were added to capture sufficient detail of the circumstances of exposure, such as "To your best recollection, which of these best describes who you were with when you first saw pornography online...I was with a friend/a group of friends". A question around exposure intention included the response: "It was intentional - I searched for it on YouTube or other streaming site".

\section{Affective Responses to IP (Initial and Current Exposure)}

These items were designed to measure the degree to which respondents were desensitised to IP (i.e. had a diminished emotional response after repeated exposure to IP) through their early exposure to IP (Martellozzo et al., 2016). The first affective responses to IP scale required participants to click on as many responses that they recalled feeling at their 
initial exposure to IP. Response choices included "curious", "turned on", "shocked" and "ashamed". The second affective responses question (after an intervening item) was identical and asked respondents to identify their current affective responses to IP. For both initial and current scales, the total number of positive affective responses selected was summed and divided by the total number of possible positive affective responses (5) to calculate a total positive affective response score for each respondent. This was repeated for the total number of possible negative affective responses (9) to calculate a total negative affective response score for each respondent. As respondents could select as many (or as few) affective responses as they wished, it was not possible to assess scale reliability.

\section{Negative Cognitive Appraisals of IP}

This scale consists of 13 items on a 4-point Likert scale ranging from 1 (strongly disagree) to 4 (strongly agree) (Martellozzo et al., 2016). Examples of items include "Most online porn that I have seen was... degrading/humiliating" and "informative/educational". Five positive valence items were reverse scored before scores were summed to calculate an overall negative cognitive appraisal of IP score, with higher scores indicating a more negative view overall of IP. The Cronbach alpha was 0.82 .

\section{IP-Related Sexual Beliefs}

Nine items assessed the influence of IP on respondent sexual beliefs on a 4-point Likert scale ranging from 1 (strongly disagree) to 4 (strongly agree) in this scale partially based on a scale by Martellozzo et al. (2016). An example of an item was "Seeing online pornography has led me to believe that the things people do in IP are the kinds of sexual behaviours that are normal in most sexual relationships". Higher scores indicated a perceived higher influence of IP on respondent sexual beliefs. The Cronbach alpha was 0.88 .

\section{Perceived Problematic IP Use}

Nine items assessed the individual's perceived addiction to IP on a 7-point Likert scale ranging from 1 (do not agree at all) to 7 (extremely agree). The CPUI-9 (Grubbs et al., 2015) is based on the original 32-item Cyber Pornography Use Inventory and consists of three 3-item subscales: perceived compulsivity (e.g. "I feel unable to stop my use of online pornography"), access efforts (e.g. "I have put off important priorities to view pornography) and emotional distress (e.g. "I feel sick after viewing pornography online"). Scores were computed for each subscale as well as a total scale score, identified in this study as "PIP Viewing". Only the total scale score was used in analyses. The Cronbach alpha for the total scale was 0.83 .

\section{Sensation Seeking}

We had hoped to use the Arnett Inventory of Sensation Seeking (AISS: Arnett, 1994), a 20-item scale designed to measure the novelty and intensity components of sensation seeking. Although the scale demonstrated adequate internal reliability $(\alpha=0.70)$ in a study involving adolescents (Arnett, 1994), reliability in the current sample was low $(\alpha=0.61)$. Both item analysis and factor analysis failed to improve scale reliability, and the decision was therefore made to exclude this scale from further analysis.

\section{Dissociative Experiences Scale Taxon}

The Dissociative Experiences Scale Taxon (DES-T) is an eight-item subscale of the full 28-item Dissociative Experiences Scale (DES) (Carlson \& Putnam, 1993; Waller \& Ross, 1997). Each item is scored on a scale from 0 to 100 (percent of the time dissociative experience occurs), with the overall score calculated as the mean of the eight items (Waller, 2000). This measure of the frequency of dissociative experiences in daily life allows individuals to quantify their own experiences on a sliding scale. Two primary themes are represented by the DES-T items: (a) amnesia for dissociative states and (b) derealisation or depersonalization (Waller \& Ross, 1997). The Cronbach alpha was 0.88 .

\section{Sexual Impulsivity}

Regulation of sexual urges was measured using the 13 item control subscale of the Compulsive Sexual Behaviour Inventory (CSBI), a 28-item self-report measure of the severity of compulsive sexual behaviour (Coleman et al., 2001). The control subscale assesses the control of sexual urges and behaviour (e.g., "have you felt unable to control your sexual behaviour?") as well as the interpersonal, professional and financial consequences (e.g., "How often have your sexual thoughts or behaviours interfered with the formation of friendships?") and the distress associated with compulsive sexual behaviour (e.g., "How often have you had sex or masturbated more than you wanted to?"). The scale is scored from one (never) to five (very frequently), with higher scores indicating greater sexual compulsivity. The Cronbach alpha was 0.84 .

\section{Procedure}

Respondents were recruited via the author's university Psychology Participant Pool and signed up to gain course credit. The invitation to participate advised students that they would 
be completing an anonymous online research study on Internet pornography, which would take 25 to $30 \mathrm{~min}$ to complete. They were also advised that they had to be aged 17 and 25 years and have previously viewed IP to participate. After reading the study description and providing consent, they were given a link to the study online platform and were presented with a participant information and consent form. Participants were then asked screener questions (i.e. confirmation of previously viewing IP) to determine eligibility (ineligible participants were diverted from the study). Respondents then answered demographic and Internet use questions followed by a battery of scales. The survey concluded with information about where to seek assistance if completion of the study had caused any distress.

\section{Results}

\section{Data Screening}

A preliminary examination was performed to check the distributions of the residuals from analyses. The distribution of the residuals for the self-assessed PIP viewing measure showed a clear positive skew with some indication of fanning, suggesting violation of the normality and equality of variance assumptions. To address non normality, bootstrapping with a bias and accelerated confidence interval (BCa) was utilised for the $t$ tests and the final regression predicting self-assessed PIP viewing. The regression analyses revealed one respondent with a Mahalanobis distance that far exceeded the critical value (Tabachnick \& Fidell, 2013), so this case was removed for all analysis.

\section{Circumstances of Exposure to IP}

Whilst most respondents $(59.4 \%)$ indicated their first exposure to IP was deliberate, more than a third (39\%) were exposed accidentally. Of those exposed accidentally, $33.5 \%$ cited the unexpected downloading of IP via a link as the exposure source, whilst others reported the material unexpectedly downloaded through file sharing (2.6\%), or they received IP through an unwanted email (2.9\%). Most respondents (43.9\%) reported viewing IP for the first time on a desktop computer, but a large number $(27.5 \%)$ were exposed on a portable computer or handheld device (28.1\%).

\section{IP Viewing: Affective Responses and Cognitive Appraisals of IP}

Consistent with the first hypothesis, positive affective responses to IP were found to be negatively correlated with a negative cognitive appraisal of IP and positively correlated with higher viewing frequency. Full results are presented in Table 1.

\section{Prediction of Negative Cognitive Appraisals of IP}

A multiple linear regression was calculated to predict a negative cognitive appraisal of IP from negative affective responses to IP at first exposure and negative affective responses to IP at current exposure. As predicted in Hypothesis 1, a significant regression equation was found $(F(2,367)=67.51, p<.001)$. The total variance explained by the model as whole was $27 \%$. Higher negative affective responses to IP at initial exposure and higher negative affective responses to IP at current exposure were both significant predictors of a negative cognitive appraisal of IP. Full results are presented in Table 2.

\section{Age of First Exposure to IP and IP Viewing Frequency by Gender}

Most respondents (41.3\%) recalled their first exposure to IP as occurring between 12 and 14 years of age. Males tended to be exposed earlier to IP than females with $5.6 \%$ of males (1.8\% of females) recalling exposure as early as $6-8$ years, $28.2 \%$ (23.7\%) recalling exposure at $9-11$ years and $57.3 \%$ (33.7\%) recalling their initial exposure between 12 and 14 years. Almost a quarter of females (23\%) and only $10 \%$ of males recalled first being exposed to IP between 15 and 17 years. Around $37 \%$ of males and $8.5 \%$ of females indicated they watched IP every day or several times a week. A further $30.9 \%$ of males and $10 \%$ of females reported watching IP at least once a week and $17.3 \%$ of males and $20 \%$
Table 1 Pearson correlation coefficients for current Internet pornography (IP) viewing frequency, negative cognitive appraisal of IP, positive and negative affective responses at both initial and current exposure to IP

\begin{tabular}{|c|c|c|c|c|c|c|}
\hline Measure & 1 & 2 & 3 & 4 & 5 & 6 \\
\hline 1. IP Viewing Frequency & - & & & & & \\
\hline 2. Negative Cognitive Appraisal of IP & $-.42^{* *}$ & - & & & & \\
\hline 3. Positive Affective Responses (Initial) & $.37^{* *}$ & $-.37^{* *}$ & - & & & \\
\hline 4. Positive Affective Responses (Current) & $.50^{* *}$ & $-.39^{* *}$ & $.41^{* *}$ & - & & \\
\hline 5. Negative Affective Responses (Initial) & $-.24^{* *}$ & $.40^{* *}$ & $-.29^{* *}$ & -.03 & - & \\
\hline 6. Negative Affective Responses (Current) & $-.34^{* *}$ & $.49^{* *}$ & $-.17^{* *}$ & $-.23^{* *}$ & $.49^{* *}$ & - \\
\hline
\end{tabular}

$*<.05 ; * *<.01 ; * * *<.001$ 
Table 2 Multiple linear regression analyses predicting negative cognitive appraisal of Internet pornography from negative affective responses at initial and current exposure

\begin{tabular}{llllll}
\hline Variable & $B$ & $S E B$ & $\beta$ & $t$ & $p$ \\
\hline Neg Affect CURRENT & 1.62 & .22 & .39 & 7.50 & $<.001$ \\
Neg Affect INITIAL & .67 & .16 & .21 & 4.07 & $<.001$ \\
\hline
\end{tabular}

Neg Affect CURRENT refers to negative affective responses to IP at current exposure. Neg affect INITIAL refers to negative affective responses to IP at first exposure

of females viewed IP a few times a month. As predicted in hypothesis two, higher scores on self-assessed PIP viewing were positively correlated with earlier exposure to IP ( $p=$ $0.12, p<0.05)$ and higher IP viewing frequency $(r=0.28$, $p<.001)$.

\section{Age of Initial Exposure to IP, Negative Cognitive Appraisal of IP, Frequency of Viewing and PIP Viewing by Gender}

Independent sample $t$ tests were used to compare the scores of males and females for negative cognitive appraisal of IP, frequency of IP viewing and self-assessed PIP viewing. As Levene's test indicated inequality in the variances between the male and female groups, and a positive skew in the PIP viewing variable, bootstrapping was employed utilising a bias corrected and accelerated confidence interval (BCa). Consistent with the second hypothesis, on average, male respondents cognitively appraised IP less negatively (mean difference $=3.79$ ), viewed IP more frequently (mean difference $=1.67$ ) and were more likely to assess their IP viewing as problematic (mean difference $=.48$ ) than female respondents. Full results are displayed below in Table 3. As the dependent variable for age of initial exposure was measured in ordinal categories, it could not be treated as continuous. A Mann-Whitney $U$ test was therefore utilised. It revealed a significant difference in the age of exposure between males and females, $U=12,103, \mathrm{z}=-2.966$,

Table 3 Descriptive statistics and bootstrapped confidence intervals for independent sample $t$ test for negative cognitive appraisal of IP, IP viewing frequency and self-assessed problematic IP viewing by gen- $p=.003, r=0.15$, such that male respondents indicated being exposed to IP earlier than female respondents.

\section{IP-Related Sexual Beliefs}

Respondents were asked if and how IP influenced their sexual beliefs in relation to factors such as gender-based sexual expectations; the determination of sexually appealing physical features and other ways IP may be associated with their specific sexual beliefs. A bootstrapped independent sample $t$ test was conducted to compare the average scores of males and females. Consistent with the third hypothesis, there was no significant effect for gender, $t(367)=-1.83$, $p=.07$, mean difference $=-1.043$, despite the average score for females $(M=18.64, S E=0.32)$ being slightly higher than the average male score $(M=17.60, S E=0.44)$.

\section{Psychopathological Predisposing Factors and PIP Viewing}

As predicted in the fourth hypothesis, self-assessed PIP viewing was positively correlated with all the psychopathological vulnerability measures and with higher scores on the IP sexual beliefs measure. Pearson's correlations are presented in Table 4.

\section{Prediction of PIP Viewing}

Due to violations of the assumptions of normality of errors and homoscedasticity, bootstrapping methods with biascorrected intervals were utilised to test the final hypothesis relating to the prediction of self-assessed PIP viewing. The predictor variables included in the model were gender, age of initial exposure to IP, IP viewing frequency, positive affective responses to IP at initial and current exposure, depression, dissociation, sexual impulsivity and IP-related sexual beliefs. Age of initial exposure and respondent gender were entered as dummy coded categorical variables. All other predictors were treated as numeric. Contrary to the

der with bootstrapping and bias corrected and accelerated confidence intervals $(\mathrm{BCa})$

\begin{tabular}{|c|c|c|c|c|c|c|c|c|c|c|}
\hline \multirow[t]{3}{*}{ Outcome } & \multicolumn{6}{|l|}{ Group } & \multirow{3}{*}{$\begin{array}{l}\mathrm{BCa} \\
95 \% \mathrm{CI}\end{array}$} & \multirow[b]{3}{*}{$t$} & \multirow[b]{3}{*}{ sig. } & \multirow[b]{3}{*}{$f^{2}$} \\
\hline & \multicolumn{3}{|l|}{ Male } & \multicolumn{3}{|c|}{ Female } & & & & \\
\hline & $M$ & $S D$ & $n$ & $M$ & $S D$ & $n$ & & & & \\
\hline Negative Cog & 19.93 & 5.89 & 107 & 23.71 & 6.30 & 259 & $2.39,5.18$ & 5.33 & $<.001$ & .61 \\
\hline Viewing Freq & 4.80 & 1.49 & 107 & 3.14 & 1.54 & 259 & $-2.01,-1.32$ & -9.52 & $<.001$ & -1.1 \\
\hline PIP viewing & 2.19 & 0.88 & 107 & 1.70 & .73 & 259 & $-0.68,-0.29$ & -5.02 & $<.001$ & -.62 \\
\hline
\end{tabular}

Bootstrapping conducted with 2000 bias corrected samples 
Table 4 Pearson correlation coefficients for self-assessed PIP viewing and vulnerability measures

\begin{tabular}{|c|c|c|c|c|c|}
\hline Measure & 1 & 2 & 3 & 4 & 5 \\
\hline 1. PIP viewing & - & & & & \\
\hline 2. Depression & $.22^{* *}$ & - & & & \\
\hline 3. Dissociation & $.18^{* *}$ & $.39^{* *}$ & - & & \\
\hline 4. Sexual impulsivity & $.45^{* *}$ & $.31^{* * *}$ & $.28^{* *}$ & - & \\
\hline 5. IP sexual beliefs & $.19^{* *}$ & $.12^{*}$ & $.17^{* *}$ & $.20^{* *}$ & - \\
\hline
\end{tabular}

$*<.05 ; * *<.01 ; * * *<.001$

fourth hypothesis, the overall effect for age of exposure was not significant, $F(5,336)=1.56, p=.171$. Similarly, the overall effect for gender was not significant $F(1,336)=1.60$, $p=.207$. The total variance explained by the model as a whole was $33 \%, F(18,336)=9.20, p<.001$. In the final model, frequency of IP viewing, positive affective responses at current exposure, sexual impulsivity and IP-related sexual beliefs were all significant predictors of PIP viewing. Full results for numeric variables are presented in Table 5.

\section{Discussion}

\section{Exposure to IP and IP Viewing}

Consistent with prior studies, these findings indicate IP consumption begins early and is widespread (Chen et al., 2013; Flood, 2009; Martellozzo et al., 2016). Whilst more than two in five respondents recalled their first IP exposure between 12 and 14 years of age, for just under a quarter, initial exposure occurred between 9 and 11 years. This result is analogous to prior UK findings where $94 \%$ of adolescents surveyed indicated being exposed to IP by 14 years (Martellozzo et al., 2016) and US research, where the average age of first exposure was 11 years (Maltz \& Maltz, 2008). On average, male respondents recalled being

Table 5 Multiple linear regression analyses predicting self-assessed PIP viewing from individual and situational vulnerability measures with bootstrapping and bias corrected and accelerated confidence intervals (BCa)

\begin{tabular}{lcccc}
\hline Variable & \multicolumn{1}{l}{$B$} & SE B & $p$ & \multicolumn{1}{l}{ Bca 95\% CI } \\
\hline Frequency of IP viewing & .09 & .03 & .005 & $.024, .140$ \\
Pos Affect FIRST & -.05 & .03 & .082 & $-.109, .008$ \\
Pos Affect CURR & -.08 & .03 & .007 & $-.135,-.022$ \\
Depression & .01 & .01 & .051 & $.001, .025$ \\
Dissociation & .00 & .00 & .411 & $-.003, .006$ \\
Sexual Impulsivity & .04 & .01 & .001 & $.024, .048$ \\
IP Sexual Beliefs & .03 & .01 & .001 & $.012, .038$ \\
\hline
\end{tabular}

Table displays results for numeric variables only. Age of initial exposure and respondent gender were entered as dummy coded categorical variables exposed to IP earlier than females, which is also consistent with prior studies (Flood, 2010; Janghorbani \& Lam, 2003; Martellozzo et al., 2016; Peter \& Valkenburg, 2006).

\section{Exposure to IP: Affective and Cognitive Responses and Viewing Frequency}

In line with the first hypothesis, positive affective responses to IP were associated with higher viewing frequency and the tendency to cognitively appraise IP less negatively. As expected, higher negative affective responses to IP at both initial and current exposure were both significant predictors of a more negative cognitive appraisal of IP. These results suggest initial emotional responses to IP may be an important prompt in how individuals cognitively appraise IP overall and consequently how frequently they subsequently view IP.

As predicted in the second hypothesis, male respondents recalled being exposed to IP earlier, cognitively appraised IP less negatively, viewed IP more frequently and were more likely to self-assess their IP viewing as problematic. This accords with prior empirical studies which indicate that males use IP more frequently, find it more enriching and report fewer negative effects from their viewing (Hald \& Malamuth, 2008; Janghorbani \& Lam, 2003; Træen et al., 2004), whilst females are less likely to describe IP as arousing and more likely to describe it as repulsive, upsetting or shocking (Herrman \& Bordner, 1983; Martellozzo et al., 2016; Traeen \& Daneback, 2013). However, other studies have shown women to both consume IP and to report being sexually aroused by it (Davis et al., 2020; Johansson \& Hammarén, 2007). It is possible some women appraise IP more negatively as a consequence of their unease about the physical or sexual expectations of them that may arise as a result of their sexual partner's consumption of IP (Häggström-Nordin et al., 2009; Tylka \& Kroon Van Diest, 2015). In a qualitative study with young women, participants expressed concern about the expectations of their boyfriends if they watched IP together, with the pornographic script found to function as a frame of reference for both physical ideals and sexual performance (Löfgren-Mårtenson \& Månsson, 2010). 


\section{PIP Viewing}

This study found that around 1 in 6 male participants compared to 1 in 20 female participants believe they are "addicted to IP" and some are already experiencing interpersonal and professional consequences from their IP viewing, including delaying priorities or avoiding socialising in order to view IP. The gender differences in the overall scores on the PIP viewing measure were not unexpected given previous empirical findings. It has also been suggested that there are unique dimensions to IP that make it particularly potent in its ability to elicit compulsive behaviour. Specifically, in addition to the captivating access, affordability, and anonymity (the Triple A Engine) characteristics of IP (Cooper, 1998), it has been posited that the constant pursuit of novel explicit imagery, often without achieving complete satisfaction from its viewing (Cooper et al., 2004), embodies a behavioural pattern which is analogous to the tolerance and habituation properties seen in substance addictions (Harper $\&$ Hodgins, 2016). Whilst this study did not utilise a clinical measure of addiction to IP (which is yet to be ratified as a psychiatric disorder), this data does provide some insight into the potential disruptions that IP viewing may generate for those viewers who do not feel their IP consumption is wholly within their control. Twohig et al. (2009) found that for those who describe their IP viewing as problematic, the strongest negative effects are in the psychological or spiritual domain and in actual behavioural outcomes, such as relationship impairment and problems at work or school.

As hypothesised, higher depression and dissociation scores were significantly correlated with self-assessed PIP viewing, as well as with one another, suggesting the potential comorbidity of these vulnerability factors. This relationship is consistent with previous studies that have found an association between Internet-related compulsions and mental health problems including depression, anxiety and stress (Chou, 2001; Nassehi et al., 2017; Seki et al., 2019; Yang et al., 2019). In terms of dissociation, it has been noted that when online sexual behaviour becomes compulsive, the viewer can become increasingly detached from both their own feelings and reality, a process that could also serve to distance the individual from the content (Chaney \& Chang, 2005). Relatedly, prior studies have identified that tendencies towards IP use disorder correlated positively with using IP for emotional avoidance (Baranowski et al., 2019; Bőthe et al., 2021; Laier \& Brand, 2017).

\section{Exposure and Individual Vulnerability Factors for PIP Viewing}

No single factor can be implicated in the development of PIP viewing, as many factors may confer risk, and many protective factors may potentially offset that risk (Ioannidis et al., 2018). As predicted in the fourth hypothesis and demonstrated in the bivariate relationships (Table 4) noted in this study, both affective and cognitive responses to IP may be associated with self-assessed PIP viewing. Consistent with the fourth hypothesis, the final regression analysis suggests IP viewing frequency, positive current affective responses to IP, sexual impulsivity and IP-influenced sexual beliefs may all uniquely contribute to the prediction of PIP viewing. These findings are consistent with an explanatory model of IUDs proposed by Brand et al. (2016), which the authors suggested could also apply to PIP use. Brand et al. suggest that the dysregulated behaviour seen in many IUDs is a consequence of interactions between the individual's predisposing core characteristics, affective and cognitive responses to internal or external stimuli, reduced executive function or inhibitory control and the individual's decision-making behaviour. Consistent with these proposed associations, this study found that psychopathological vulnerability factors and affective responses to IP, coupled with individual decision making around IP exposure and the relationship between IP and individual sexual beliefs, were all relevant factors in self-assessed PIP viewing. Each of the significant independent variables is examined below as predictors of PIP viewing.

\section{Impulsivity}

This study found that sexual impulsivity was significantly correlated with self-assessed PIP viewing and made a unique contribution to the model predicting PIP viewing. The compelling attributes of IP may be particularly captivating for those who already struggle to control their impulses, with a number of studies identifying impulse control problems in conjunction with problematic Internet use (Brand et al., 2016; Davis et al., 2002; Yellowlees \& Marks, 2007). Davis et al. (2002) found decreased impulse control predicted troublesome Internet use in the workplace, whilst another study found that when confronted with pornographic cues, participant symptom severity of IP use disorder was associated with reduced executive functioning (Schiebener et al., 2015). Antons and Brand (2018) likewise found that both trait and state impulsivity play an important role in the development of IP use disorders, with reduced inhibitory control contributing to the loss of control over IP use, notwithstanding negative personal consequences.

\section{Affective Responses to IP}

This study also asked young people to reflect on their first exposure to IP and recall how they felt initially and what they think about IP currently. Each respondent was 
required to determine the authenticity of those recalled emotions and make a judgement on their overall assessment of IP. These affective responses were not mutually exclusive, making it possible for a person to both be aroused and troubled by the content they view (or indeed by their own arousal). In addition to making a unique contribution to the model predicting PIP viewing, positive emotional responses to IP were found to be significantly positively correlated with viewing frequency. Similarly, negative emotional responses were significantly negatively correlated with viewing frequency. Although the current study cannot determine the causal mechanisms underlying these effects, one explanation may be that sustained exposure to IP following early exposure facilitates a process of desensitisation. Frequent exposure to explicit sexual material has been found to rapidly diminish adverse reactions such as repulsion and disgust and to subsequently facilitate the development of enjoyment reactions (Martellozzo et al., 2016; Paul, 2010; Zillmann, 2000). Thus, it may be that desensitisation to any unpalatable aspects of IP may allow IP viewing to become a more frequent pastime and for some, for this viewing to become problematic.

\section{IP-Related Sexual Beliefs}

As predicted in the third hypothesis, it was found that both males and females were equally likely to report that IP is to some extent, shaping their sexual beliefs. This result was noted despite the relatively more negative cognitive appraisal of IP by females compared to males. One explanation for this inconsistency may be that many women experience a degree of ambivalence in relation to their IP viewing, as a consequence of both how realistic and acceptable they perceive IP to be, given the prevailing heterosexual IP narrative (Häggström-Nordin et al., 2006; Peter \& Valkenburg, 2006). Mainstream heterosexual IP often depicts a narrative of males as sexually dominant and females as submissive participants, often manipulated or coerced into sexual activity (Gorman et al., 2010; Gossett \& Byrne, 2002; Klaassen \& Peter, 2015; Whisnant, 2016). Thus, some young women may experience a degree of cognitive dissonance as they attempt to reconcile imagery that they may find simultaneously arousing and debasing of their gender (Galatzer-Levy, 2012; Martellozzo et al., 2016). IP-related sexual beliefs also made a statistically significant contribution to the prediction of PIP viewing in the final regression model. This finding is consistent with prior studies suggesting that even if women are less likely to view IP as realistic, it may still be linked to beliefs about the acceptability of different sexual practices and behaviours for both genders (Häggström-Nordin et al., 2006; Peter \& Valkenburg, 2016).

\section{Frequency of IP Viewing}

It was notable that nearly two in five males and one in ten females indicated they were viewing IP either daily or several times a week. Viewing frequency was also significantly correlated with earlier age of initial exposure, selfassessed PIP viewing and made a statistically significant unique contribution to the prediction of self-assessed PIP viewing. Whilst some studies have found an association between age of exposure and problematic IP use (Harper \& Hodgins, 2016), other studies have not confirmed this effect (Baranowski et al., 2019; Štulhofer et al., 2008). Nevertheless, the association between frequency of viewing and PIP viewing is in accord with the findings of Harper and Hodgins (2016), who found that whilst frequency of use was not directly correlated with negative psychosocial outcomes, a dramatic shift in compulsive IP use was noted when participants were using IP once a day or more. Importantly, studies have found that high frequency users of IP are more likely to report psychosocial difficulties such as loneliness, anxiety, depressive symptoms and a poorer quality of life (Weaver et al., 2011; Yoder et al., 2005).

\section{Strengths and Limitations}

This study represents an initial foray into a complex area and has provided insights into both recalled early exposure to IP and self-assessed IP-related sexual beliefs. To our knowledge, this is the first study to examine the relationships between exposure factors such as age of initial exposure to IP and frequency of viewing and person factors such as affective and cognitive responses to IP, potential psychopathological vulnerability factors and PIP viewing. These relationships were also examined utilising some novel modified measures examining affective and cognitive responses to IP and IP-related sexual beliefs, which could be validated further in future empirical studies.

The IP exposure and IP-related beliefs measures also relied heavily on recall and self-report as the most direct way to assess each construct. Whilst this has the advantage of recognising the unique self-knowledge and awareness each individual has of their relationship with IP, these types of measures are disadvantaged by the ability of respondents to distort their responses deliberately to manage their view of themselves or, unintentionally, through faulty recall (Gravetter \& Forzano, 2018). Similarly, the self-assessed PIP viewing measure was reliant on subjective perceptions of the individual, as opposed to any objective clinical measure of PIP viewing. Although still valuable, this measure has been found to be vulnerable to the effects of factors such as religiosity (Grubbs et al., 2017) including "moral incongruence" experienced when viewing IP, leading some religious 
individuals to consider any IP viewing as problematic (Grubbs et al., 2019). In retrospect, controlling for religiosity may have been important, and this should be considered in future similar studies.

Unfortunately, the sensation seeking measure included in this data collection was not psychometrically adequate to include in analyses. It may be valuable for future studies of susceptibility factors in PIP viewing to use a better validated measure of sensation seeking. As with all cross-sectional studies, causality conclusions were not possible in this study, and thus further longitudinal and experimental research in this area seems warranted. Given this study utilised a cohort of undergraduate university students, it would also be valuable for future studies to use more heterogenous samples that are gender balanced.

\section{Conclusion}

This study examined IP use by emerging adults, in terms of the person and situational factors that might be associated with self-assessed PIP viewing. Affective and cognitive responses to IP and whether IP was in any way associated with the sexual beliefs of viewers was also examined. Whilst beliefs do not equate to actual influence, they can provide some important preliminary insights into what role IP might be playing in the sexual socialisation of some young people. Pornography consumption has certainly crossed over from being a clandestine habit to being a recognised part of popular culture (Crabbe \& Corlett, 2011; Flood, 2007), and for some individuals, this has presented challenges. Given that many factors implicated in the aetiology of PIP viewing may not be mutable, it is essential that any mediating and moderating factors that can be modified through clinical intervention are identified early (Brand et al., 2016).

This study found that IP exposure factors, psychopathological vulnerability factors, affective responses to IP and the endorsement of IP-related sexual beliefs are important factors to consider in identifying those for whom IP viewing may become problematic. Importantly, many of these factors can be directly mitigated, such as by addressing early exposure risks through school-based education programs that help young people judiciously evaluate this material before deciding if they wish to incorporate IP narratives into their own sexual behaviours. This would recognise the critical and agentic capacities of many older adolescents and emerging adults, once they have the knowledge to make these judgements. It is also important for clinicians and policy makers to gain an understanding of what factors differentiate adolescents and emerging adults who develop PIP viewing behaviour from those who do not, as these insights can assist in the creation of more efficacious prevention and treatment programs.
Author Contribution All authors contributed to the study conception and design. Material preparation, data collection and analysis were performed by Shireen Bernstein and Wayne Warburton. The first draft of the manuscript was written by Shireen Bernstein, and all authors commented on previous versions of the manuscript. All authors read and approved the final manuscript.

Funding Open Access funding enabled and organized by CAUL and its Member Institutions.

Availability of Data and Material Not available.

Code Availability Not applicable.

\section{Declarations}

Conflict of Interest The authors declare no competing interests.

Open Access This article is licensed under a Creative Commons Attribution 4.0 International License, which permits use, sharing, adaptation, distribution and reproduction in any medium or format, as long as you give appropriate credit to the original author(s) and the source, provide a link to the Creative Commons licence, and indicate if changes were made. The images or other third party material in this article are included in the article's Creative Commons licence, unless indicated otherwise in a credit line to the material. If material is not included in the article's Creative Commons licence and your intended use is not permitted by statutory regulation or exceeds the permitted use, you will need to obtain permission directly from the copyright holder. To view a copy of this licence, visit http://creativecommons.org/licenses/by/4.0/.

\section{References}

Albright, J. M. (2008). Sex in America online: An exploration of sex, marital status, and sexual identity in internet sex seeking and its impacts. The Journal of Sex Research, 45(2), 175-186. https:// doi.org/10.1080/00224490801987481

Antons, S., \& Brand, M. (2018). Trait and state impulsivity in males with tendency towards Internet-pornography-use disorder. Addictive Behaviors, 79, 171-177. https://doi.org/10.1016/j.addbeh. 2017.12.029

Arnett, J. (1994). Sensation seeking: A new conceptualization and a new scale. Personality and Individual Differences, 16(2), 289296. https://doi.org/10.1016/0191-8869(94)90165-1

Arnett, J. J. (2006). Emerging adulthood: Understanding the new way of coming of age. American Psychological Association. https:// doi.org/10.1037/11381-001

Baranowski, A. M., Vogl, R., \& Stark, R. (2019). Prevalence and determinants of problematic online pornography use in a sample of German women. The Journal of Sexual Medicine, 16(8), 12741282. https://doi.org/10.1016/j.jsxm.2019.05.010

Borgogna, N. C., \& Aita, S. L. (2019). Problematic pornography viewing from a big-5 personality perspective. Sexual Addiction \& Compulsivity, 26(3-4), 293-314. https://doi.org/10.1080/10720162. 2019.1670302

Bőthe, B., Tóth-Király, I., Bella, N., Potenza, M. N., Demetrovics, Z., \& Orosz, G. (2021). Why do people watch pornography? The motivational basis of pornography use. Psychology of Addictive Behaviors. https://doi.org/10.1037/adb0000603

Brand, M., Young, K. S., \& Laier, C. (2014). Prefrontal control and internet addiction: A theoretical model and review of 
neuropsychological and neuroimaging findings. Frontiers in Human Neuroscience, 8(375). https://doi.org/10.3389/fnhum. 2014.00375

Brand, M., Young, K. S., Laier, C., Wölfling, K., \& Potenza, M. N. (2016). Integrating psychological and neurobiological considerations regarding the development and maintenance of specific Internet-use disorders: An interaction of personaffect-cognition-execution (I-PACE) model. Neuroscience \& Biobehavioral Reviews, 71, 252-266. https://doi.org/10.1016/j. neubiorev.2016.08.033

Braun, B. (1988). The BASK (behavior, affect, sensation, knowledge) model of dissociation. Dissociation, 1, 16-23.

Brown, C. C., Durtschi, J. A., Carroll, J. S., \& Willoughby, B. J. (2017). Understanding and predicting classes of college students who use pornography. Computers in Human Behavior, 66, 114-121. https://doi.org/10.1016/j.chb.2016.09.008

Carlson, E. B., \& Putnam, F. W. (1993). An update on the dissociative experience scale. Dissociation, 6(1), 16-27, 0896-2863.

Carroll, J. S., Padilla-Walker, L. M., Nelson, L. J., Olson, C. D., McNamara Barry, C., \& Madsen, S. D. (2008). Generation XXX: Pornography acceptance and use among emerging adults. Journal of Adolescent Research, 23(1), 6-30. https://doi.org/10. 1177/0743558407306348

Chaney, M. P., \& Chang, C. Y. (2005). A trio of turmoil for internet sexually addicted men who have sex with men: Boredom proneness, social connectedness, and dissociation. Sexual Addiction \& Compulsivity, 12(1), 3-18. https://doi.org/10. 1080/10720160590933671

Chen, A.-S., Leung, M., Chen, C.-H., \& Yang, S. C. (2013). Exposure to Internet Pornography Among Taiwanese Adolescents. Social Behavior and Personality, 41(1), 157-164. https://doi.org/10. 2224/sbp.2013.41.1.157

Choi, J.-S., Park, S. M., Roh, M.-S., Lee, J.-Y., Park, C.-B., Hwang, J. Y., Gwak, A. R., \& Jung, H. Y. (2014). Dysfunctional inhibitory control and impulsivity in Internet addiction. Psychiatry Research, 215(2), 424-428. https://doi.org/10.1016/j. psychres.2013.12.001

Chou, C. (2001). Internet heavy use and addiction among Taiwanese college students: An online interview study. CyberPsychology \& Behavior, 4(5), 573-585. https://doi.org/10.1089/ 109493101753235160

Coleman, M., Miner, F., Ohlerking, N., \& Raymond, E. (2001). Compulsive sexual behavior inventory: A preliminary study of reliability and validity. Journal of Sex \& Marital Therapy, 27(4), 325-332. https://doi.org/10.1080/009262301317081070

Cooper, A. (1998). Sexuality and the internet: Surfing into the new millennium. Cyberpsychology and Behaviour, 1(2), 181-187. https://doi.org/10.1089/cpb.1998.1.187

Cooper, A., Delmonico, D., Griffin-Shelley, E., \& Mathy, R. M. (2004). Online sexual activity: An examination of potentially problematic behaviors. Sexual Addiction \& Compulsivity, 11(3), 129-143. https://doi.org/10.1080/10720160490882642

Cooper, A., Putnam, D. E., Planchon, L. A., \& Boies, S. C. (1999). Online sexual compulsivity: Getting tangled in the net. Sexual Addiction \& Compulsivity, 6(2), 79-104. https://doi.org/10.1080/ 10720169908400182

Corne, S., Briere, J., \& Esses, L. M. (1992). Women's attitudes and fantasies about rape as a function of early exposure to pornography. Journal of Interpersonal Violence, 7(4), 454-461. https:// doi.org/10.1177/088626092007004002

Cowan, G., \& Campbell, R. R. (1995). Rape causal attitudes among adolescents. Journal of Sex Research, 32(2), 145-153. https:// doi.org/10.1080/00224499509551784

Crabbe, M., \& Corlett, D. (2011). Eroticising inequality: Technology, pornography and young people. Redress, 20(1), 11-15.
Dalley, J., \& w., Everitt, Barry j., \& Robbins, Trevor w. (2011). Impulsivity, compulsivity, and top-down cognitive control. Neuron, 69(4), 680-694. https://doi.org/10.1016/j.neuron.2011.01.020

Davis, A. C., Temple-Smith, M. J., Carrotte, E., Hellard, M. E., \& Lim, M. S. C. (2020). A descriptive analysis of young women's pornography use: A tale of exploration and harm. Sexual Health, 17(1), 69-76. https://doi.org/10.1071/SH19131

Davis, K. C., Norris, J., George, W. H., Martell, J., \& Heiman, J. R. (2006). Rape-myth congruent beliefs in women resulting from exposure to violent pornography: Effects of alcohol and sexual arousal. Journal of Interpersonal Violence, 21(9), 1208-1223. https://doi.org/10.1177/0886260506290428

Davis, R. A., Flett, G. L., \& Besser, A. (2002). Validation of a new scale for measuring problematic internet use: Implications for pre-employment screening. CyberPsychology \& Behavior, 5(4), 331-345. https://doi.org/10.1089/109493102760275581

Döring, N. M. (2009). The internet's impact on sexuality: A critical review of 15 years of research. Computers in Human Behavior, 25(5), 1089-1101. https://doi.org/10.1016/j.chb.2009.04. 003

Dwulit, A. D., \& Rzymski, P. (2019). Prevalence, patterns and selfperceived effects of pornography consumption in Polish university students: A cross-sectional study. International Journal of Environmental Research and Public Health, 16(10), 1861. https://doi.org/10.3390/ijerph16101861

Fagan, P. J., Wise, T. N., Schmidt, C. W., Ponticas, Y., Marshall, R. D., \& Costa, P. T. (1991). A comparison of 5-factor personality dimensions in males with sexual dysfunction and males with paraphilia. Journal of Personality Assessment, 57(3), 434-448. https://doi.org/10.1207/s15327752jpa5703_4

Fernandez, D. P., Tee, E. Y. J., \& Fernandez, E. F. (2017). Do cyber pornography use inventory-9 scores reflect actual compulsivity in internet pornography use? Exploring the Role of Abstinence Effort. Sexual Addiction \& Compulsivity, 24(3), 156-179. https:// doi.org/10.1080/10720162.2017.1344166

Flood, M. (2007). Exposure to pornography among youth in Australia. Journal of Sociology, 43(1), 45-60. https://doi.org/10.1177/ 1440783307073934

Flood, M. (2009). The harms of pornography exposure among children and young people. Child Abuse Review, 18(6), 384-400. https:// doi.org/10.1002/car.1092

Flood, M. (2010). Young men using pornography. In K. Boyle (Ed.), Everyday Pornography. Routledge.

Galatzer-Levy, R. M. (2012). Obscuring desire: A special pattern of male adolescent masturbation, internet pornography, and the flight from meaning. Psychoanalytic Inquiry, 32(5), 480-495. https://doi.org/10.1080/07351690.2012.703582

Gorman, S., Monk-Turner, E., \& Fish, J. (2010). Free adult internet web sites: How prevalent are degrading acts? Gender Issues, 27(3), 131-145. https://doi.org/10.1007/s12147-010-9095-7

Gossett, J. L., \& Byrne, S. (2002). "Click here" a content analysis of internet rape sites.(Abstract). Gender \& Society, 16(5), 689.

Gravetter, F. J., \& Forzano, L.-A.B. (2018). Research methods for the behavioral sciences (Edition (6th ed.). Cengage.

Grubbs, J. B., Exline, J., Pargament, K., Volk, F., \& Lindberg, M. (2017). Internet pornography use, perceived addiction, and religious/spiritual struggles. The Official Publication of the International Academy of Sex Research, 46(6), 1733-1745. https://doi. org/10.1007/s10508-016-0772-9

Grubbs, J. B., Perry, S., Wilt, J. A., \& Reid, R. (2019). Pornography problems due to moral incongruence: An Integrative model with a systematic review and meta-analysis. Archives of Sexual Behavior, 48(2), 397-415. https://doi.org/10.1007/s10508-018-1248-x

Grubbs, J. B., Sessoms, J., Wheeler, D. M., \& Volk, F. (2010). The cyber-pornography use inventory: The development of a new 
assessment instrument. Sexual Addiction \& Compulsivity, 17(2), 106-126. https://doi.org/10.1080/10720161003776166

Grubbs, J. B., Volk, F., Exline, J. J., \& Pargament, K. I. (2015). Internet pornography use: Perceived addiction, psychological distress, and the validation of a brief measure. Journal of Sex \& Marital Therapy, 41(1), 83-106. https://doi.org/10.1080/0092623X.2013. 842192

Häggström-Nordin, E., Hanson, U., \& Tydén, T. (2005). Associations between pornography consumption and sexual practices among adolescents in Sweden. International Journal of STD \& AIDS, 16(107-107).

Häggström-Nordin, E., Tydén, T., Hanson, U., \& Larsson, M. (2009). Experiences of and attitudes towards pornography among a group of Swedish high school students. The European Journal of Contraception \& Reproductive Health Care, 14(4), 277-284. https://doi.org/10.1080/13625180903028171

Häggström-Nordin, E., Sandberg, J., Hanson, U., \& Tydén, T. (2006). 'It's everywhere!' Young Swedish people's thoughts and reflections about pornography. Scandinavian Journal of Caring Sciences, 20(4), 386-393. https://doi.org/10.1111/j.1471-6712.2006.00417.x

Hald, G. (2006). Gender differences in pornography consumption among young heterosexual Danish ADULTS. The Official Publication of the International Academy of Sex Research, 35(5), 577-585. https://doi.org/10.1007/s10508-006-9064-0

Hald, G. M., \& Malamuth, N. M. (2008). Self-Perceived effects of pornography consumption. The Official Publication of the International Academy of Sex Research, 37(4), 614-625. https://doi. org/10.1007/s10508-007-9212-1

Harkness, E. L., Mullan, B., \& Blaszczynski, A. (2015). Association between pornography use and sexual risk behaviors in adult consumers: A systematic review. Cyberpsychology, Behavior and Social Networking, 18(2), 59-71. https://doi.org/10.1089/cyber. 2014.0343

Harper, C., \& Hodgins, D. C. (2016). Examining Correlates of Problematic Internet Pornography Use among University Students., 5(2), 179. https://doi.org/10.1556/2006.5.2016.022

Herrman, M. S., \& Bordner, D. C. (1983). Attitudes toward pornography in a Southern community. Criminology, 21(3), 349-374. https://doi.org/10.1111/j.1745-9125.1983.tb00266.x

Innala, S. (2007). Pornography on the net: Same attraction, but new options. Sexologies, 16(2), 112-120. https://doi.org/10.1016/j. sexol.2006.12.010

Ioannidis, K., Treder, M. S., Chamberlain, S. R., Kiraly, F., Redden, S. A., Stein, D. J., Lochner, C., \& Grant, J. E. (2018). Problematic internet use as an age-related multifaceted problem: Evidence from a two-site survey. Addictive Behaviors, 81, 157-166. https:// doi.org/10.1016/j.addbeh.2018.02.017

Janghorbani, M., \& Lam, T. H. (2003). The youth sexuality study task force. sexual media use by young adults in Hong Kong: Prevalence and associated factors. Archives of Sexual Behavior, 32, 545-553. https://doi.org/10.1023/A:1026089511526

Johansson, T., \& Hammarén, N. (2007). Hegemonic masculinity and pornography: Young People's attitudes toward and relations to pornography. The Journal of Men's Studies, 15(1), 57-70. https:// doi.org/10.3149/jms.1501.57

Klaassen, M. J. E., \& Peter, J. (2015). Gender (In)equality in internet pornography: A content analysis of popular pornographic internet videos. Journal of Sex Research, 52(7), 721-735. https://doi. org/10.1080/00224499.2014.976781

Laier, C., \& Brand, M. (2017). Mood changes after watching pornography on the internet are linked to tendencies towards internetpornography-viewing disorder. Addictive Behaviors Reports, 5(C), 9-13. https://doi.org/10.1016/j.abrep.2016.11.003

Lee, B., \& Tamborini, R. (2005). Third-Person effect and internet pornography: The influence of collectivism and internet self-efficacy. Journal of Communication, 55(2), 292-310. https:// doi.org/10.1111/j.1460-2466.2005.tb02673.x

Lee, H. W., Choi, J.-S., Shin, Y.-C., Lee, J.-Y., Jung, H. Y., \& Kwon, J. S. (2012). Impulsivity in internet addiction: A comparison with pathological gambling. Cyberpsychology, Behavior, and Social Networking, 15(7), 373-377. https://doi.org/10.1089/cyber.2012. 0063

Lim, M. S. C., Agius, P. A., Carrotte, E. R., Vella, A. M., \& Hellard, M. E. (2017). Young Australians' use of pornography and associations with sexual risk behaviours. Australian and New Zealand Journal of Public Health, 41(4), 438-443. https://doi.org/10. 1111/1753-6405.12678

Lo, V.-H., \& Wei, R. (2002). Third-person effect, gender, and pornography on the internet. Journal of Broadcasting \& Electronic Media, 46(1), 13-33. https://doi.org/10.1207/ s15506878jobem4601_2

Löfgren-Mårtenson, L., \& Månsson, S.-A. (2010). Lust, love, and life: A qualitative study of Swedish adolescents' perceptions and experiences with pornography. The Journal of Sex Research, 47(6), 568-579. https://doi.org/10.1080/00224490903151374

Lu, H.-Y., Ma, L.-C., Lee, T.-S., Hou, H.-Y., \& Liao, H.-Y. (2014). The link of sexual sensation seeking to acceptance of cybersex, multiple sexual partners, and one-night stands among Taiwanese college students. Journal of Nursing Research, 22(3), 208-215. https://doi.org/10.1097/jnr.0000000000000043

Maddox, A., Rhoades, G., \& Markman, H. (2011). Viewing sexuallyexplicit materials alone or together: Associations with relationship quality. The Official Publication of the International Academy of Sex Research, 40(2), 441-448. https://doi.org/10.1007/ s10508-009-9585-4

Maltz, W., \& Maltz, L. (2008). The porn trap: The essential guide to overcoming problems caused by pornography. Harper Collins.

Manning, J. C. (2006). The impact of internet pornography on marriage and the family: A review of the research. Sexual Addiction \& Compulsivity, 13(2-3), 131-165. https://doi.org/10.1080/ 10720160600870711

Marston, C., \& Lewis, R. (2014). Anal heterosex among young people and implications for health promotion: A qualitative study in the UK. British Medical Journal Open, 4(8), e004996. https://doi. org/10.1136/bmjopen-2014-004996

Martellozzo, E., Monaghan, A., Adler, J. R., Davidson, J., Leyva, R., \& Horvath, M. A. H. (2016). "I wasn't sure it was normal to watch it..."A quantitative and qualitative examination of the impact of online pornography on the values, attitudes, beliefs and behaviours of children and young people. Middlesex University, NSPCC, OCC. https://doi.org/10.6084/m9.figshare.3382393

McKee, A. (2008). The porn report Carlton, Vic.: Melbourne University Publishing.

Miller, D. J., Hald, G. M., \& Kidd, G. (2018). Self-perceived effects of pornography consumption among heterosexual men. Psychology of Men \& Masculinity, 19(3), 469-476. https://doi.org/10.1037/ men0000112

Morahan-Martin, J. (2005). Internet abuse: Addiction? Disorder? Symptom? Alternative explanations? Social Science Computer Review, 23(1), 39-48. https://doi.org/10.1177/0894439304271533

Nassehi, A., Arbabisarjou, A., \& Jafari, M. (2017). Surveying the relationship of internet addiction with dependence on cell phone, depression, anxiety, and stress in collegians. International Journal of Advanced Biotechnology Research, 7, 2267-2274.

Noar, S. M., Zimmerman, R. S., Palmgreen, P., Lustria, M., \& Horosewski, M. L. (2006). Integrating personality and psychosocial theoretical approaches to understanding safer sexual behavior: Implications for message design. Health Communication, 19(2), 165-174. https://doi.org/10.1207/ s15327027hc1902_8 
Paul, P. (2010). From pornography to porno to porn: How porn became the norm. In J. R. S. J. a. D. M. Hughes (Ed.), The Social Costs of Pornography. Witherspoon Institute.

Peter, J., \& Valkenburg, P. M. (2006). Adolescents' exposure to sexually explicit online material and recreational attitudes toward sex. Journal of Communication, 56(4), 639-660. https://doi.org/10. 1111/j.1460-2466.2006.00313.x

Peter, J., \& Valkenburg, P. M. (2016). Adolescents and pornography: A review of 20 years of research. Journal of Sex Research, 53(4-5), 509-531. https://doi.org/10.1080/00224499.2016.1143441

Rissel, C., Richters, J., de Visser, R. O., McKee, A., Yeung, A., \& Caruana, T. (2017). A profile of pornography users in Australia: Findings from the second Australian study of health and relationships. The Journal of Sex Research, 54(2), 227-240. https://doi. org/10.1080/00224499.2016.1191597

Rogala, C., \& Tydén, T. (2003). Does pornography influence young women's sexual behavior? Women's Health Issues, 13(1), 39-43. https:// doi.org/10.1016/S1049-3867(02)00174-3

Ross, M., Månsson, S.-A., \& Daneback, K. (2012). Prevalence, severity, and correlates of problematic sexual internet use in swedish men and women. The Official Publication of the International Academy of Sex Research, 41(2), 459-466. https://doi.org/10.1007/ s10508-011-9762-0

Schiebener, J., Laier, C., \& Brand, M. (2015). Getting stuck with pornography? Overuse or neglect of cybersex cues in a multitasking situation is related to symptoms of cybersex addiction. Journal of Behavioral Addictions, 4(1), 14-21. https://doi.org/10.1556/JBA.4. 2015.1.5

Seki, T., Hamazaki, K., Natori, T., \& Inadera, H. (2019). Relationship between internet addiction and depression among Japanese university students. Journal of Affective Disorders, 256, 668-672. https:// doi.org/10.1016/j.jad.2019.06.055

Stewart, D., \& Szymanski, D. (2012). Young adult women's reports of their male romantic partner's pornography use as a correlate of their self-esteem, relationship quality, and sexual satisfaction. $A$ Journal of Research, 67(5), 257-271. https://doi.org/10.1007/ s11199-012-0164-0

Štulhofer, A., Buško, V., \& Landripet, I. (2010). Pornography, sexual socialization, and satisfaction among young men. The Official Publication of the International Academy of Sex Research, 39(1), 168-178. https://doi.org/10.1007/s10508-008-9387-0

Štulhofer, A., Jelovica, V., \& Ružić, J. (2008). Is early exposure to pornography a risk factor for sexual compulsivity? Findings from an online survey among young heterosexual adults. International Journal of Sexual Health, 20(4), 270-280. https://doi.org/10.1080/ 19317610802411870

Sun, C., Bridges, A., Johnson, J. A., \& Ezzell, M. B. (2016). Pornography and the Male Sexual Script: An Analysis of Consumption and Sexual Relations., 45(4), 983. https://doi.org/10.1007/ s10508-014-0391-2

Sussman, S., \& Arnett, J. J. (2014). Emerging adulthood. Evaluation \& the Health Professions, 37(2), 147-155. https://doi.org/10.1177/ 0163278714521812

Svedin, C. G., Akerman, I., \& Priebe, G. (2011). Frequent users of pornography. A population based epidemiological study of Swedish male adolescents. Journal of Adolescence, 34(4), 779-788. https:// doi.org/10.1016/j.adolescence.2010.04.010

Tabachnick, B. G., \& Fidell, L. S. (2013). Using multivariate statistics (6th edition). Boston Pearson.

Traeen, B., \& Daneback, K. (2013). The use of pornography and sexual behaviour among Norwegian men and women of differing sexual orientation.(Report). Sexologies, 22(2), e41-e48. https://doi.org/10. 1016/j.sexol.2012.03.001

Træen, B., Spitznogle, K., \& Beverfjord, A. (2004). Attitudes and use of pornography in the norwegian population 2002. The Journal of Sex Research, 41(2), 193-200.
Twohig, M. P., Crosby, J. M., \& Cox, J. M. (2009). Viewing internet pornography: For whom is it problematic, how, and why? Sexual Addiction \& Compulsivity, 16(4), 253-266. https://doi.org/10.1080/ 10720160903300788

Tydén, T., Olsson, S.-E., \& Häggström-Nordin, E. (2001). Improved use of contraceptives, attitudes toward pornography, and sexual harassment among female university students. Women's Health Issues, 11(2), 87-94. https://doi.org/10.1016/S1049-3867(00) 00096-7

Tylka, T. L. (2015). No harm in looking, right? Men's pornography consumption, body image, and well-being. Psychology of Men \& Masculinity, 16(1), 97-107. https://doi.org/10.1037/a0035774

Tylka, T. L., \& Kroon Van Diest, A. M. (2015). You looking at her "hot" body may not be "cool" for me: Integrating male partners' pornography use into objectification theory for women. Psychology of Women Quarterly, 39(1), 67-84. https://doi.org/10.1177/ 0361684314521784

Valkenburg, P. M., Peter, J., \& Walther, J. B. (2016). Media effects: Theory and research. Annual Review of Psychology, 67(1), 315-338. https://doi.org/10.1146/annurev-psych-122414-033608

Waller, G. (2000). Rebuilding shattered lives: The responsible treatment of complex post-traumatic and dissociative disorders. 8 . https:// doi.org/10.1002/1099-0968(200008)8:4\%3C330::AID-ERV361\% 3E3.0.CO2-T

Waller, N. G., \& Ross, C. A. (1997). The prevalence and biometric structure of pathological dissociation in the general population: Taxometric and behavior genetic findings. Journal of Abnormal Psychology, 106(4), 499-510. https://doi.org/10.1037/0021-843X. 106.4.499

Watson, M. A., \& Smith, R. D. (2012). Positive porn: Educational, medical, and clinical uses. American Journal of Sexuality Education, 7(2), 122-145. https://doi.org/10.1080/15546128.2012.680861

Weaver, J. B., Weaver, S. S., Mays, D., Hopkins, G. L., Kannenberg, W., \& McBride, D. (2011). Mental- and physical-health indicators and sexually explicit media use behavior by adults. The Journal of Sexual Medicine, 8(3), 764-772. https://doi.org/10.1111/j.17436109.2010.02030.x

Weinberg, M., Williams, C., Kleiner, S., \& Irizarry, Y. (2010). Pornography, normalization, and empowerment. Archives of Sexual Behavior, 39(6), 1389-1401. https://doi.org/10.1007/s10508-009-9592-5

Weitzer, R. (2011). Pornography's effects: the need for solid evidence: A review essay of everyday pornography, edited by Karen Boyle and Pornland: How porn has hijacked our sexuality, by Gail Dines Violence Against Women, 17(5), 666-675. https://doi.org/10.1177/ 1077801211407478

Whisnant, R. (2016). Pornography, humiliation, and consent. Sexualization, Media, \& Society, 2(3). https://doi.org/10.1177/ 2374623816662876

Wiers, R. W., Ames, S. L., Hofmann, W., Krank, M., \& Stacy, A. W. (2010). Impulsivity, impulsive and reflective processes and the development of alcohol use and misuse in adolescents and young adults. Frontiers in Psychology, 1, 1664-1078.

Wright, P. J. (2013). A Three-wave longitudinal analysis of preexisting beliefs, exposure to pornography, and attitude change. Communication Reports, 26(1), 13-25. https://doi.org/10.1080/08934215. 2013.773053

Wright, P. J., \& Arroyo, A. (2013). Internet pornography and U.S. Women's sexual behavior: Results from a national sample. Mass Communication \& Society, 16(5), 617-638. https://doi.org/10.1080/ 15205436.2012 .754045

Wright, P. J., \& Randall, A. K. (2012). Internet pornography exposure and risky sexual behavior among adult males in the United States. Computers in Human Behavior, 28(4), 1410-1416. https://doi.org/ 10.1016/j.chb.2012.03.003

Wright, P. J., \& Tokunaga, R. (2016). Men's objectifying media consumption, objectification of women, and attitudes supportive of 
violence against women. International Academy of Sex Research, 45(4), 955-964. https://doi.org/10.1007/s10508-015-0644-8

Wright, P. J., Tokunaga, R. S., \& Kraus, A. (2016). A meta-analysis of pornography consumption and actual acts of sexual aggression in general population studies. Journal of Communication, 66(1), 183-205. https://doi.org/10.1111/jcom.12201

Yang, S. Y., Fu, S. H., Chen, K. L., Hsieh, P. L., \& Lin, P. H. (2019). Relationships between depression, health-related behaviors, and internet addiction in female junior college students. PLoS One, 14(8), e0220784. https://doi.org/10.1371/journal.pone.0220784

Yellowlees, P. M., \& Marks, S. (2007). Problematic internet use or internet addiction? Computers in Human Behavior, 23(3), 1447-1453. https://doi.org/10.1016/j.chb.2005.05.004
Yoder, V. C., Virden, T. B., \& Amin, K. (2005). Internet pornography and loneliness: An association? Sexual Addiction \& Compulsivity, 12(1), 19-44. https://doi.org/10.1080/10720160590933653

Zillmann, D. (2000). Influence of unrestrained access to erotica on adolescents' and young adults' dispositions toward sexuality. Journal of Adolescent Health, 27(2), 41-44. https://doi.org/10. 1016/S1054-139X(00)00137-3

Publisher's Note Springer Nature remains neutral with regard to jurisdictional claims in published maps and institutional affiliations. 